\title{
Non-Classical Gluconeogenesis-Dependent Glucose Metabolism in Rhipicephalus microplus Embryonic Cell Line BME26
}

\author{
Renato Martins da Silva ${ }^{1,2}$, Bárbara Della Noce ${ }^{1}$, Camila Fernanda Waltero ${ }^{1,3}$, \\ Evenilton Pessoa Costa ${ }^{1}$, Leonardo Araujo de Abreu 1,3, Naftaly Wang'ombe Githaka ${ }^{2}$, \\ Jorge Moraes ${ }^{3}$, Helga Fernandes Gomes ${ }^{3}$, Satoru Konnai ${ }^{2}$, Itabajara da Silva Vaz Jr. ${ }^{4}$, \\ Kazuhiko Ohashi ${ }^{2}$ and Carlos Logullo ${ }^{1, *}$
}

1 Laboratory of Chemistry and Function of Proteins and Peptides, Animal Experimentation Unit, UENF, Av. Alberto Lamego, 2000, Horto, CEP 28013-602 Campos dos Goytacazes, RJ, Brazil; E-Mails: rjrenato@ig.com.br (R.M.S.); babifal@yahoo.com.br (B.D.N.); kmhilaf@hotmail.com (C.F.W.); eveniltonpessoa@yahoo.com.br (E.P.C.); leoabreu@gmail.com (L.A.A.)

2 Laboratory of Infectious Diseases, Graduate School of Veterinary Medicine, Hokkaido University, Kita 18, Kita-ku Sapporo 060-0818, Japan; E-Mails: naftalygitahi@yahoo.com (N.W.G.); konnai@vetmed.hokudai.ac.jp (S.K.); kazu@chem.kyushu-univ.jp (K.O.)

3 Laboratory of Biochemistry Hatisaburo Masuda, Institute of Medical Biochemistry, Federal University of Rio de Janeiro, NUPEM-UFRJ/Macaé, Campus Macaé, Avenida São José do Barreto, São José do Barreto, CEP 27965-045 Macaé, RJ, Brazil; E-Mails: jlcmoraes@yahoo.com.br (J.M.); hgomes2@yahoo.com.br (H.F.G.)

4 Center of Biotechnology, Federal University of Rio Grande do Sul, C.P. 15005, Av. Bento Gonçalves 9500, Prédio 43421, Campos do Vale, CEP 91501-970 Porto Alegre, RS, Brazil; E-Mail: itabajara.vaz@ufrgs.br

* Author to whom correspondence should be addressed; E-Mail: carloslogullo@yahoo.com.br; Tel.: +55-22-98806-0245.

Academic Editor: Marcello Iriti

Received: 7 October 2014 / Accepted: 31 December 2014 / Published: 14 January 2015

\begin{abstract}
In this work we evaluated several genes involved in gluconeogenesis, glycolysis and glycogen metabolism, the major pathways for carbohydrate catabolism and anabolism, in the BME26 Rhipicephalus microplus embryonic cell line. Genetic and catalytic control of the genes and enzymes associated with these pathways are modulated by alterations in energy resource availability (primarily glucose). BME26 cells in media were investigated
\end{abstract}


using three different glucose concentrations, and changes in the transcription levels of target genes in response to carbohydrate utilization were assessed. The results indicate that several genes, such as glycogen synthase (GS), glycogen synthase kinase 3 (GSK3), phosphoenolpyruvate carboxykinase (PEPCK), and glucose-6 phosphatase (GP) displayed mutual regulation in response to glucose treatment. Surprisingly, the transcription of gluconeogenic enzymes was found to increase alongside that of glycolytic enzymes, especially pyruvate kinase, with high glucose treatment. In addition, RNAi data from this study revealed that the transcription of gluconeogenic genes in BME26 cells is controlled by GSK-3. Collectively, these results improve our understanding of how glucose metabolism is regulated at the genetic level in tick cells.

Keywords: metabolism; gluconeogenesis; glycolysis; tick; gene expression; glucose

\section{Introduction}

The cattle tick Rhipicephalus microplus is an ectoparasite found in tropical and subtropical regions. Its importance in veterinary lies in its ability to transmit pathogens. It causes considerable losses in the cattle industry, with substantial damage to livestock [1]. Together, the economic losses caused by R. microplus parasitism and costs associated with its control in Brazil are estimated at 3 billion U.S. dollars a year [2].

Currently, few studies have investigated the mechanisms underlying energy metabolism during embryonic development in R. microplus or in the BME26 tick cell line [3]. Recent works have provided some insights into the dynamic processes that accompany nutrient utilization during tick embryogenesis [4-6].

Embryogenesis has been classically described as an energy-consuming process $[7,8]$. For oviparous organisms, the embryonic stage is characterized by the mobilization of metabolites of maternal origin for the development of new tissues and organs [9]. Studying the molecules involved in metabolic pathways during embryogenesis could reveal regulatory networks that control metabolism during embryonic development in numerous organism species. However, despite the recent advancements in molecular information, our understanding of genetic regulatory mechanisms, including that controlling energy metabolism, remains incomplete. In fact, many relevant aspects of metabolism during embryogenesis are not studied to the appropriate extent at present; however, essential pathways, such as those related to carbohydrate metabolism, are likely to be highly conserved among important disease vectors, including ticks and mites.

During embryogenesis, before blastoderm formation (a landmark stage of tick embryonic development), glycogen reserves are preferentially mobilized to support the energy-intensive process of embryogenesis [5]. Subsequently, protein degradation and gluconeogenesis intensify, in order to supply the embryo with sufficient glucose to allow glycogen resynthesis. Thus, the use of amino acids as a substrate for gluconeogenesis and the subsequent glycogen resynthesis play an important role during the stages of $R$. microplus embryogenesis. Glycogen is the main energy source during the early stages of R. microplus embryogenesis, and protein degradation increases during late embryogenesis [5]. Protein 
metabolism depends strongly on the substantial expression and activity of carbohydrate metabolism enzymes. The opposite is true for Aedes aegypti mosquitoes, with glycogen and protein levels decreasing $24 \mathrm{~h}$ into embryonic development, with a concomitant increase in the activity of phosphoenolpyruvate carboxykinase (PEPCK), a key gluconeogenic enzyme [10]. Thus, energy homeostasis is maintained by glycogen and protein mobilization at the end of mosquito embryonic development. However, the molecular mechanisms that regulate this process are poorly understood at present. Previous work by our group investigated the insulin-signaling pathway (ISP) and its possible role during embryogenesis, using the BME26 cell line as a model [3]. Compared with untreated cells, exogenous insulin elevated the cell glycogen content in the absence of fetal calf serum (FCS). Moreover, in the presence of PI3K inhibitors (wortmannin or LY294002), these effects were blocked. These results strongly suggested the presence of an insulin-responsive system in BME26 cells that may correlate with carbohydrate/glycogen metabolism during embryogenesis. GSK3 knockdown in R. microplus females resulted in a strong reduction in GSK-3 expression in ovaries, followed by significant reductions in both oviposition and hatching [11]. Moreover, similar effects were observed in females treated with GSK3 inhibitors (alsterpaullone, bromo-indirubin-oxime-6, and indirubin-3-oxime). The appearance of the eggs also changed with these treatments, suggesting an important role for GSK3 in proper embryonic development. Another recent study reported that monoclonal antibodies for triosephosphate isomerase (TIM) inhibited BME26 cell growth [6], providing further evidence of the importance of glucose metabolism in cell proliferation. However, few studies have addressed the molecular mechanisms that control the expression of genes that are central to energy metabolism. Our previous works focused on distinct protein targets involved in tick energy metabolism, with the aim of improving our understanding of tick physiology.

BME26 cells were initially characterized by Esteves et al. [12]. Since then, BME26 cells have been used to examine regulators of glycogen metabolism under experimental conditions $[3,12]$. The objective of the present study was to investigate the transcriptional profiles of important genes involved in energy metabolism in BME26 cells cultured under three different conditions: (i) cells treated with a high glucose concentration $(100 \mathrm{mM})$; (ii) cells treated with a low glucose concentration (without additional glucose); and (iii) cells maintained under standard glucose concentration (50 $\mathrm{mM}$ ) that is used in BME26 maintenance media (control cells). Glycolysis, gluconeogenesis, glycogenolysis and glycogen synthesis pathways have been described in other organisms [4,5,10]. Research about these genes is important for the understanding of genetic causes of flux through these pathways in tick cells, with the aim of further elucidating arthropod physiology. In this regard, the development of tick cell cultures has presented great opportunities for performing experiments under controlled conditions, interfering with metabolic pathways, and understanding the processes underlying genetic regulatory networks, metabolic fluxes, and the regulation of energy homeostasis. Thus, characterizing the expression patterns of key enzymes in energy metabolism in ticks [4,5,12] may yield new targets for developing novel acaricides and other interventions to control $R$. microplus infestations. 


\section{Results and Discussion}

Ticks are adapted to survive under different environmental conditions, including periods of low energy availability, e.g., during starvation $[13,14]$. These and other studies have suggested that alternative metabolic strategies, some exclusive to ticks, may exist under different environmental conditions. In the present work, the transcription of genes that regulate energy metabolism in R. microplus was characterized using the BME26 embryonic cell line cultured in the presence of high or low glucose concentrations. These different glucose concentrations were selected based on the glucose necessary to maintain the cell line under normal condition $(50 \mathrm{mM})$, duplicating this glucose amount (100 mM, called high-glucose cells) or not adding the usual glucose amount (remaining with $3.125 \mathrm{mM}$, called low-glucose). Alterations in glucose availability affect the expression profiles of genes that encode glycolytic/gluconeogenic enzymes, as well as genes involved in glycogen metabolism, and in catabolic and anabolic pathways. Glycolysis is classically considered the principal pathway for carbohydrate catabolism, and pyruvate kinase (PK) and hexokinase (HK) are key enzymes in regulating this pathway. In the present work, the transcription of PK and HK was significantly increased in cells treated with a high glucose concentration (Figure 1). In mammals, these transcriptional changes were observed in cells after high glucose treatment [15]. In the current case, it is likely that the glycolytic pathway in tick cells accelerates, in response to greater glucose availability in the cytoplasm, because key enzymes for carbohydrate metabolism were highly up-regulated. A large number of genes show high expression in response to high carbohydrate feeding, including PK and HK in cultured hepatocytes $[16,17]$. Both of these glycolytic enzymes exhibit increases in the amounts of mRNA and protein, showing a clear sensitivity to glucose levels [18,19]. This hypothesis of sharpest glycolysis is supported by our data, whereby an increase in PK activity was observed in cells under high glucose treatment (Figure 1D), compared with the other conditions. Another glycolytic regulatory limiting step is triose phosphate isomerase (TIM), which also participates in gluconeogenesis. The TIM transcription level remained unchanged under varying glucose treatments relative to the control (data not shown). Because TIM reciprocally regulates both the carbohydrate catabolic and anabolic pathways [20], changes in substrate availability in these pathways probably do not alter TIM transcription, unlike other key enzymes exclusive to the glycolysis pathway, such as HK and PK (Figure 1).

Interestingly, HK exhibited a higher relative transcription level in the cells treated with a low glucose concentration (Figure 1A), while HK activity remained unaltered during the same treatment (Figure 1C), underlining a differential relationship between transcriptional and enzymatic regulation for this enzyme. HK is responsible for phosphorylating glucose at carbon 6 to generate glucose-6-phosphate, allowing it to be trapped inside the cell and to be channeled into the glycolytic pathway, the pentose phosphate pathway, or glycogen synthesis, and relies on a refined allosteric regulation mechanism [21]. Thus, HK activity possibly will present a different response of the transcriptional rate. In the presence of high glucose concentration, HK activity and transcription increased, as observed for PK. Our data also shows a higher oxygen consumption during high glucose treatment (Figure 2), suggesting (in addition with HK and PK) an increased level of glycolysis specific to this condition, not with the low glucose treatment. 

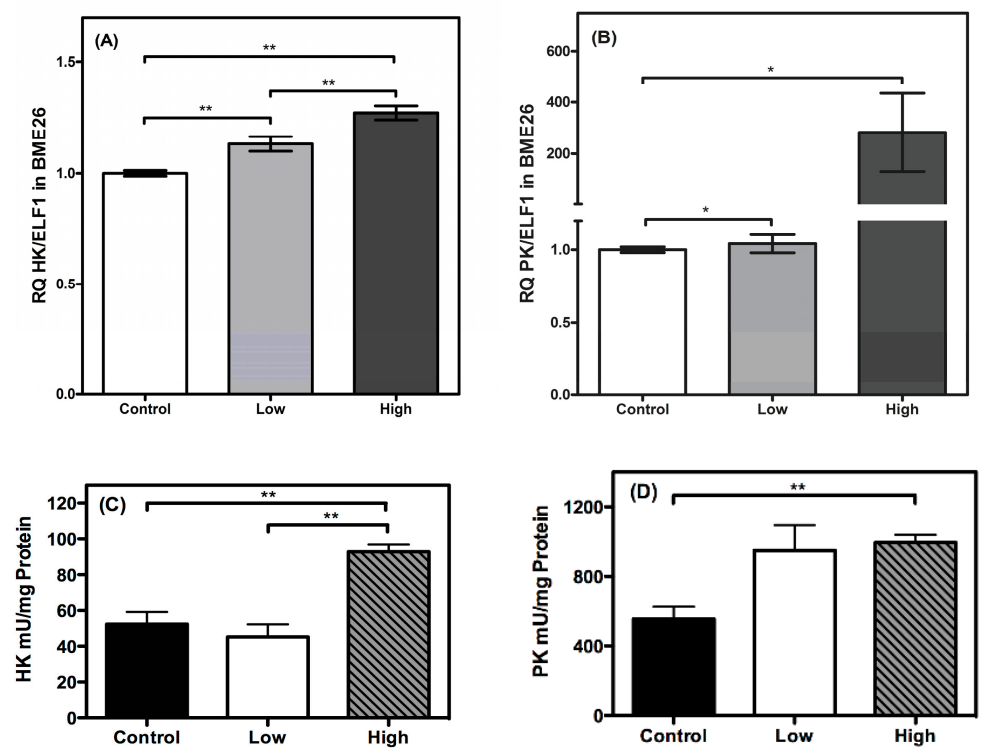

Figure 1. Transcriptional and activities of glycolytic enzymes are glucose concentration-dependent in BME26 cells. Transcriptional analysis of hexokinase (A); pyruvate kinase (B); HK activity (C) and pyruvate kinase activity (D), glycolytic key-enzymes, in embryonic Rhipicephalus microplus cells (BME26) in response to glucose treatment. Control: cells maintained with $50 \mathrm{mM}$ of glucose; Low: cell maintained without glucose addition; and High: cells maintained with $100 \mathrm{mM}$ of glucose. The experiment was performed with three independent biological samples in three experimental replicates each (* $p<0.05 ; * * p<0.001$, ANOVA).

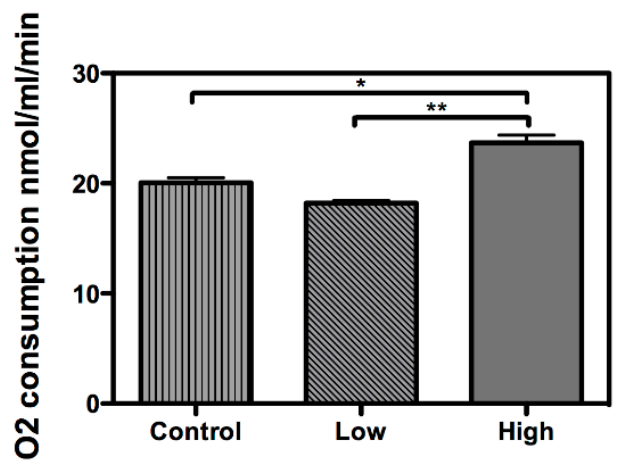

Figure 2. Higher oxygen consumption under high-glucose treatment. The oxygen consumption rate was measured in embryonic Rhipicephalus microplus cells (BME26) in response to glucose treatment. Control: cells maintained with $50 \mathrm{mM}$ of glucose; Low: cell maintained without glucose addition; and High: cells maintained with $100 \mathrm{mM}$ of glucose. The experiment was performed with three independent biological samples in three experimental replicates each $(* p<0.05 ; * * p<0.001$, ANOVA).

A cell viability assay was performed for the three culture conditions (Figure 3). With low glucose treatment, cell viability was lower than with other treatments. However, cell viability was enhanced with treatment with a high glucose concentration, when compared to control (cells maintained with a usual glucose concentration). Mitochondrial hexokinase activity is critical for sustaining constant 
ADP steady-state cycling, which in turn reduces the membrane potential and consequently decreases mitochondrial ROS formation, as previously described in rat brain cells [22,23]. Thus, glucose supports an increase in HK activity, leading to oxidative stress protection and higher cell survival [23]. Furthermore, if glucose availability is extremely high, the mitochondrial hexokinase activity decreases when ADP is produced. In this case, ROS production leads to a decrease in cell viability [24]. In this study, an increase in glucose disposal under high glucose condition is likely to improve the cell's energetic fitness, resulting in higher viability, unlike cells cultured in low glucose levels. Furthermore, the microscopy analysis with propidium iodide did not show loss of membrane integrity, in any treatment (Figure 4).

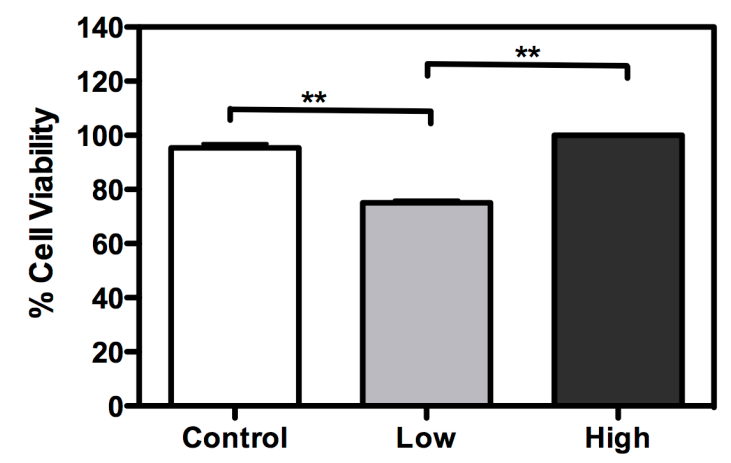

Figure 3. Glucose availability has an essential role in BME26 cell survival. Cell viability was performed in embryonic Rhipicephalus microplus cells (BME26) in response to glucose treatment. Control: cells maintained with $50 \mathrm{mM}$ of glucose; Low: cell maintained without glucose addition; and High: cells maintained with $100 \mathrm{mM}$ of glucose. The experiment was performed with three independent biological samples in three experimental replicates each $(* * p<0.001$, ANOVA).

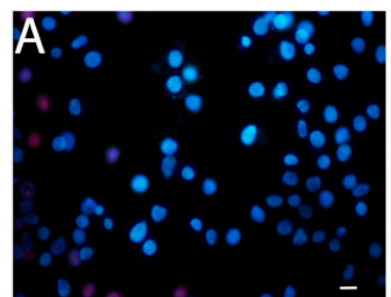

Control

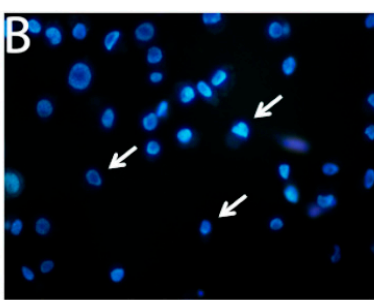

Low

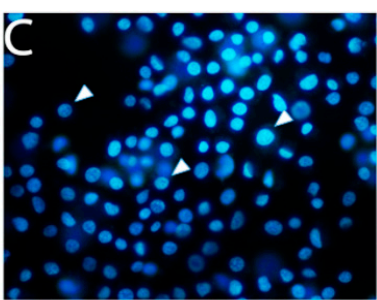

High

Figure 4. Membrane integrity is unaffected in BME26 cells after glucose treatment. The cells were directly stained by adding Hoechst 33342 and propidium iodide. Glass slides were observed in a fluorescence microscope (model Eclipse 80i, Nikon), and pictures were obtained at $400 \times$ magnification. Control: cells maintained with $50 \mathrm{mM}$ of glucose (A); Low: cell maintained without glucose addition (B); and High: cells maintained with $100 \mathrm{mM}$ of glucose $(\mathbf{C})$. The arrows indicate the shape of low-glucose cells and the triangles indicate the rounded shape of high-glucose cells. Scale bar: $10 \mu \mathrm{m}$.

The regulation of glycogen synthesis and degradation is a complex process that involves several enzymes and control points, and it is highly sensitive to changes in cell energy balance $[25,26]$. When the insulin-signaling pathway (ISP) is activated in response to elevated glucose, GSK3 activity is 
reduced and GS phosphorylation (inhibition) is blocked [27,28]. Under this condition, GS remains active and catalyzes glycogen synthesis. In BME26 cells, it was recently demonstrated that ISP was activated in response to exogenous insulin with increased glycogen levels [3], and these effects were cancelled out in the presence of PI3K inhibitors (wortmannin or LY294002). However, a transcriptional analysis of the genes involved in glycogen synthesis and degradation has not been reported in tick cells.

GSK3 transcription was elevated in the cells treated with low glucose concentrations in the present study. This enzyme participates in numerous cellular processes, including the regulation of GS by phosphorylation [27]. Apparently, a higher transcriptional level of GSK3 did not affect GS transcription in the low-glucose cells (Figure 5), reinforcing the reciprocal regulation between both enzymes that occurs at the enzymatic level. However, when the cells were treated with high amounts of glucose, GSK3 transcription was significantly reduced (Figure 5B), accompanied by an increase in GS transcription in cells under similar treatment (Figure 5A). This result may suggest the presence of mutual transcriptional regulation. Metabolic pathways that respond to cell glucose availability usually exhibit mutual transcriptional regulation [29]. In cells stimulated by insulin, AKT induces HK/GK expression [30]. A similar process is observed between PFK2/FBPase2 and HK/GK [31]. Nevertheless, high-glucose treatment can lead to increased levels of glycogen, which is normally stored under these conditions [3]. Therefore, this higher GS transcription could be directly related to an increase in the amount of glucose entering the cell, and may not be related to the reduction in GSK3 transcription itself, because the supposedly coordinated regulation between both enzymes was not observed in all the glucose treatments. Recently, Abreu et al. [32] reported that the GSK3/ATK axis in BME26 cells is involved in glycogen synthesis regulation and cell survival. AKT is a component of ISP, and phosphorylates a wide range of substrates, including GSK3, resulting in GSK3 inhibition [33,34]. AKT transcription did not change $24 \mathrm{~h}$ after the glucose treatments (data not shown). Collectively, the transcription of these enzymes appears to respond to changes in glucose availability and may share a mutual genetic regulation.

The regulation of glycogen mobilization was assessed by analyzing PGM and GDE transcription. Both enzymes are involved in glycogen polymer degradation. GDE cleaves the $\alpha-1,6$-glycosidic bond between adjacent glucose molecules in the glycogen polymer, assisting glycogen phosphorylase and PGM [35,36]. PGM transcription is elevated in low-glucose cells (Figure 6B). This result suggests a type of genetic regulation that increases the transcript level of PGM when glucose availability is low and glycogen mobilization is necessary. On the other hand, the transcription of GDE does not change when glucose amounts are low (Figure 6A). However, when the cells were treated under high-glucose conditions, GDE transcription increased significantly, indicating a differential genetic regulation in relation to PGM. 

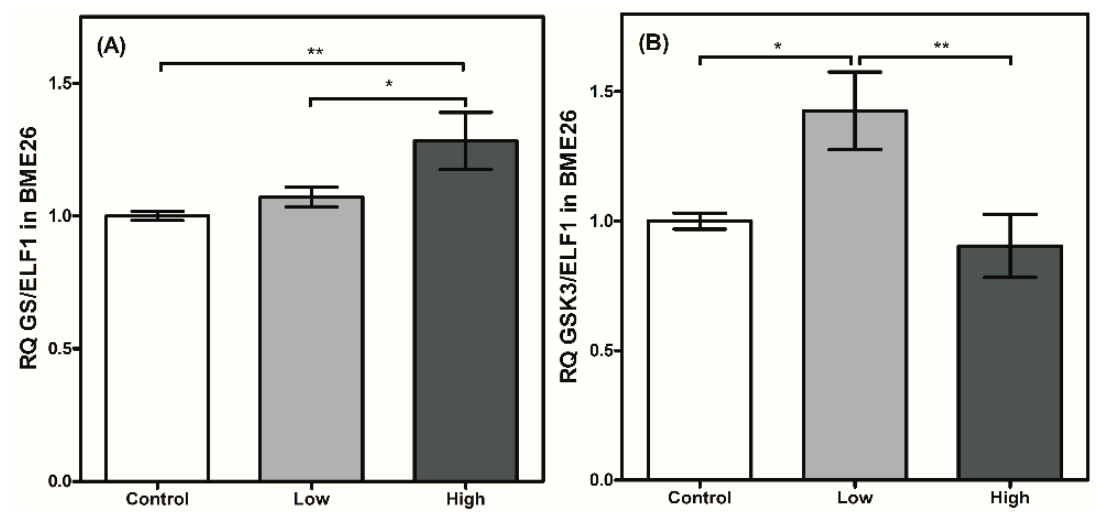

Figure 5. Glycogen metabolism synthesis has a transcriptional control in BME26 cells. Transcriptional analysis of glycogen synthase (A) and glycogen synthase kinase 3 (B) in embryonic Rhipicephalus microplus cells (BME26) in response to glucose treatment. Control: cells maintained with $50 \mathrm{mM}$ of glucose; Low: cell maintained without glucose addition; and High: cells maintained with $100 \mathrm{mM}$ of glucose. The experiment was performed with three independent biological samples in three experimental replicates each $(* p<0.05 ; * * p<0.001$, ANOVA $)$.
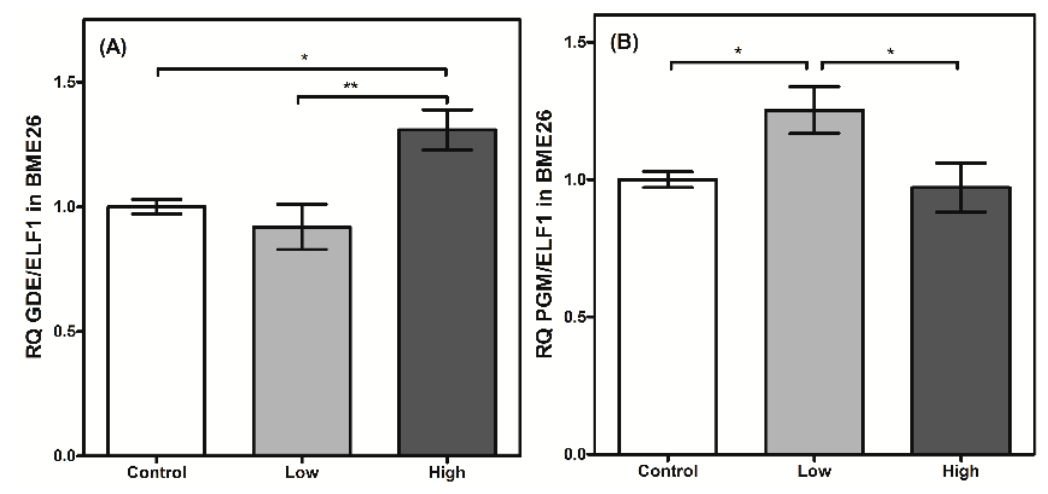

Figure 6. Glycogen degradation has a transcriptional control in BME26 cells. Transcriptional analysis of glycogen debranching enzyme (A) and phosphoglucomutase (B) in embryonic Rhipicephalus microplus cells (BME26) in response to glucose treatment. Control: cells maintained with $50 \mathrm{mM}$ of glucose; Low: cell maintained without glucose addition; and High: cells maintained with $100 \mathrm{mM}$ of glucose. The experiment was performed with three independent biological samples in three experimental replicates each $(* p<0.05$; $* * p<0.001$, ANOVA).

Gluconeogenesis produces glucose from non-glycosidic compounds, and it is an important strategy for the maintenance of cell energy homeostasis. PEPCK and GP are regulatory enzymes that catalyze the initial and final steps of gluconeogenesis, respectively [37,38]. GP removes a phosphate from glucose-6-phosphate to produce free glucose. Both enzymes exhibited similar transcriptional profiles across glucose treatments, showing reduced amounts of transcripts in the low glucose-treated cells (Figure 7). In the high-glucose cells, the opposite was observed, with increased transcription levels of both PEPCK and GP. Under normal physiological conditions, when glucose levels become low, as in starvation, the gluconeogenic flux accelerates [39,40]. In such cases, it is expected that these enzymes 
will undergo higher transcription when glucose levels are reduced, particularly PEPCK, as an enzyme that is mainly regulated by transcription in mammals. Surprisingly, in BME26 cells, this transcriptional profile was reversed. In cell culture, because there are no groups of specialized cells as seen in vivo, glucose dephosphorylation catalyzed by GP would result in the release of glucose and, consequently, the loss of this metabolite. Cells treated with low glucose may lack carbohydrate reserves [15], and a decrease in GP transcription is necessary to avoid the additional loss of glucose content. On the other hand, GP transcription increases in high-glucose cells. Massillon [41] observed an increase in GP transcription when glucose levels were elevated in hepatocyte cell culture, showing a dose-dependent response. The uptake of large amounts of glucose and the consequent phosphorylation of glucose inhibits HK activity as a result of elevated glucose-6-phosphate levels, leading to ROS generation by mitochondria [22]. In the context of cell culture, GP may be necessary to allow the diffusion of excess glucose away to avoid cell damage. PEPCK is also increased at the transcriptional level in high glucose-treated cells (Figure 7A). In addition to regulating gluconeogenesis, PEPCK regulates glyceroneogenesis, a pathway required for free fatty acid re-esterification to maintain an active level of triglyceride synthesis $[38,42]$. Under high carbohydrate availability, the flux through glyceroneogenesis increases [38]. Due to this phenomenon, we postulated that an increase in PEPCK transcription reflects a condition of high energy availability and possible glyceroneogenesis induction. Such genic profile in high glucose tick cells is very similar to observed in mammalian diabetic cells [43]. Interestingly, the glycolysis presented increased at this same moment, suggesting a deviation of pyruvate produced by glycolysis to gluconeogenesis or glyceroneogenesis (Figure 1). Indeed, a change in cell phenotype characterized by altered morphology was observed following glucose treatments. Cell culture heterogeneity was higher in the low-glucose cells than in control cells.
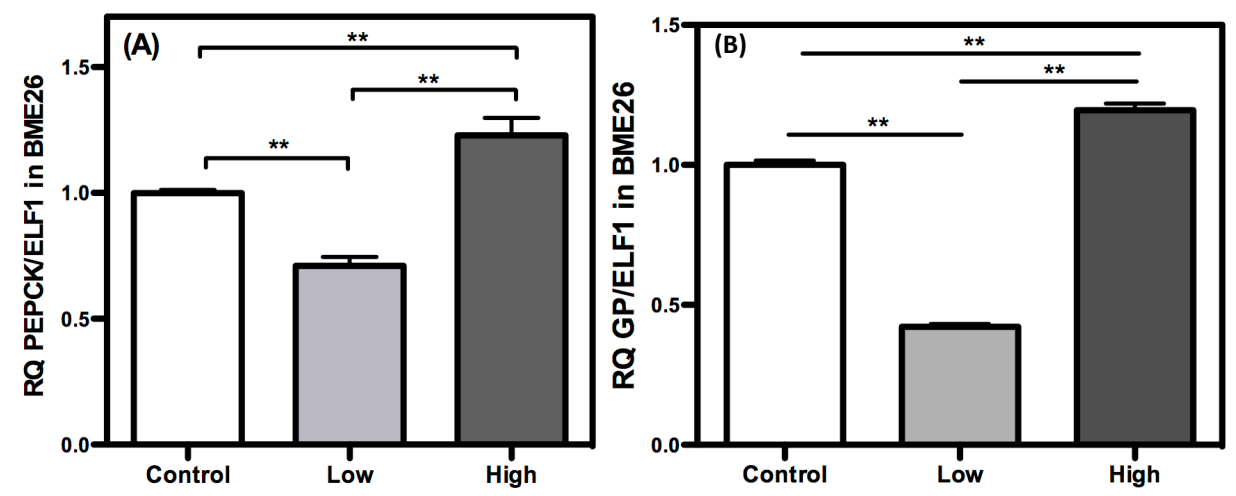

Figure 7. Gluconeogenic response increase in high glucose concentration in BME26 cells. Transcriptional analysis of PEPCK (A) and glucose-6-phosphatase (B), gluconeogenic key-enzymes, in embryonic Rhipicephalus microplus cells (BME26) in response to glucose treatment. Control: cells maintained with $50 \mathrm{mM}$ of glucose; Low: cell maintained without glucose addition; and High: cells maintained with $100 \mathrm{mM}$ of glucose. The experiment was performed with three independent biological samples in three experimental replicates each $(* * p<0.001$, ANOVA).

These results demonstrate a differential genetic regulation between cell culture and in vivo models. Nevertheless, both gluconeogenesis enzymes were regulated in a coordinated manner, with similar 
transcriptional profiles. Our group has been investigating the role of GSK3 in a wide range of metabolic processes, including gluconeogenesis. GSK3 knockdown induces increases in PEPCK and GP transcription levels (Figure 8), suggesting an indirect genetic regulation of the gluconeogenesis pathway through GSK3. A high silencing rate of essential metabolic genes usually leads to cell lethality. Specifically, a GSK3 knockdown (around 90\%) in female mosquito Aedes fluviatilis prevented them from developing their ovaries as well as egg laying. So, in a new experiment, GSK3 transcription was reduced by $30 \%$ to evaluate the effect of GSK3 inhibition on insect embryogenesis [44]. Similarly, we induced a higher efficiency in GSK3 silencing in the BME26 cells previously, leading to cell death (data not shown). Thus, a methodology was adopted to interfere in the transcriptional response, but without inducing cell death. At enzymatic level, GSK3 is regulated by phosphorylation, and a $15 \%$ of suppression may not affect the metabolism overall substantially. Effectively, the low rate in GSK3 silencing afforded to analyze the effect of GSK3 reductions in the transcription of gluconeogenesis genes.
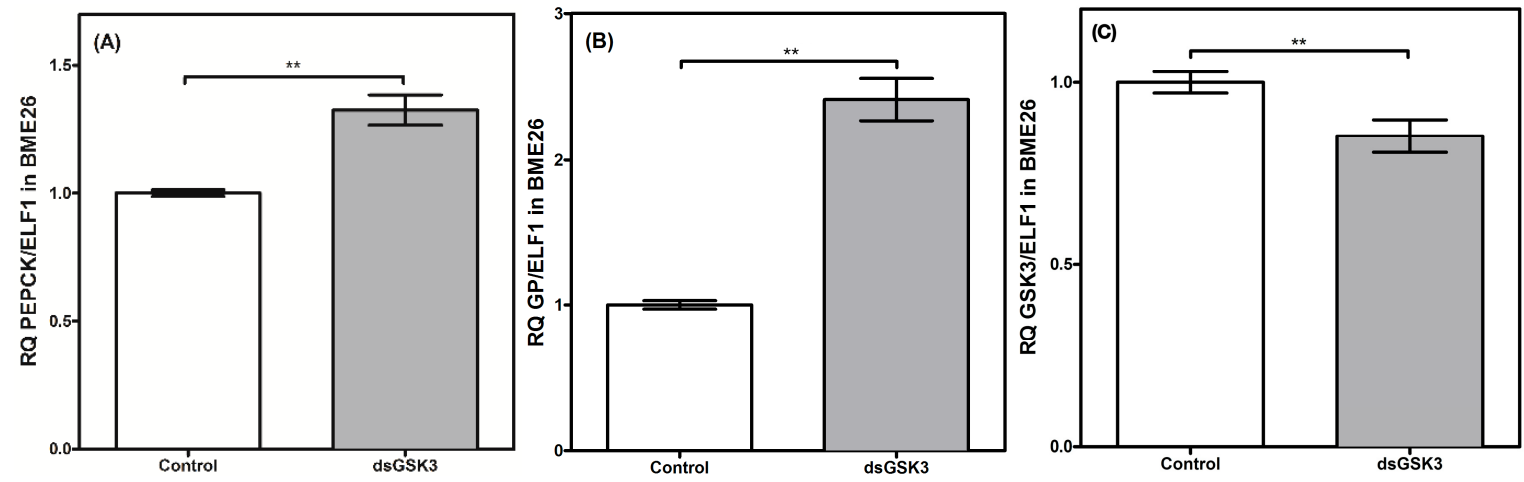

Figure 8. Gluconeogenic enzymes have transcriptional control by GSK3 in BME26 silenced-cells. Transcriptional analysis of PEPCK (A) and glucose-6 phosphatase (B), gluconeogenic key-enzymes, in embryonic Rhipicephalus microplus cells (BME26) in response to GSK3 silencing (C). Control: cells maintained with $50 \mathrm{mM}$ of glucose; Low: cell maintained without glucose addition; and High: cells maintained with $100 \mathrm{mM}$ of glucose. The experiment was performed with three independent biological samples in three experimental replicates each $(* * p<0.001$, paired T test).

To date, and to our knowledge, no mutual regulation between GSK3 and gluconeogenesis has been reported. Future studies could focus on whether there is any direct enzymatic regulation between GSK3 and other gluconeogenic enzymes. Figure 9 summarizes all metabolic and molecular changes in the respective treatments. Altogether, these results contribute to the understanding of the mechanisms that control glucose metabolism at the genetic level in the model cell line BME26. Characterizing changes in metabolic enzymes at both the transcriptional and functional levels in response to nutrient availability may lead to the identification of genes that are critical for maintaining the cellular energy balance. Moreover, this research may yield potential antigens for improved anti-tick vaccines or novel targets for acaricide action, which are urgently needed to control the tick vector $R$. microplus. 


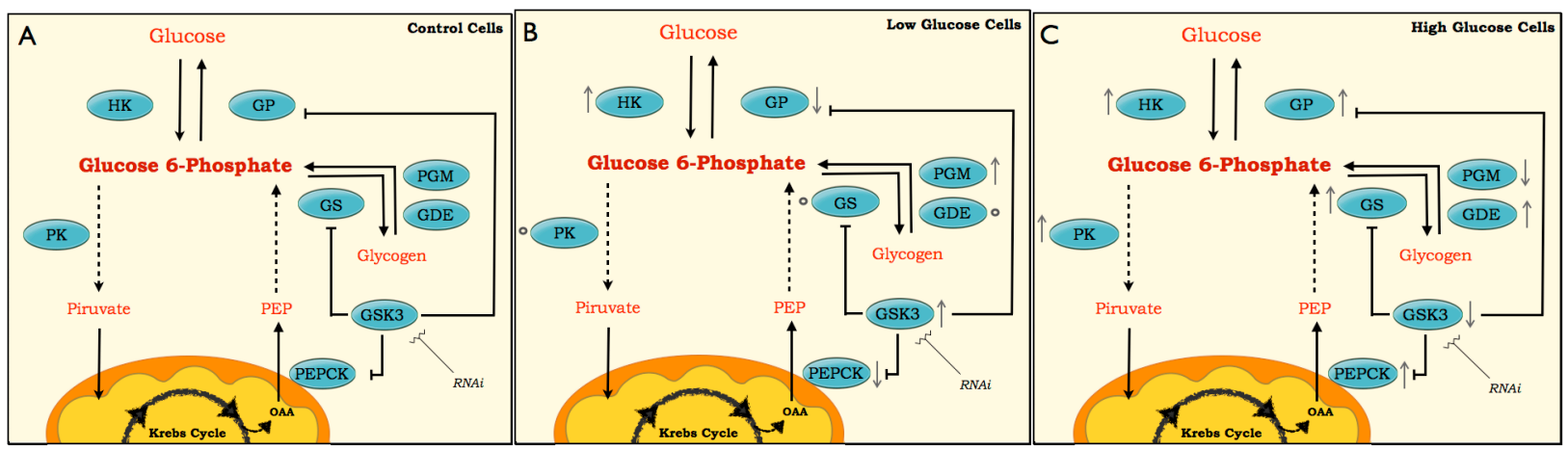

Figure 9. Scheme for pathways of glucose metabolism. The scheme is based on enzyme activities, metabolites and molecular changes in BME26 cells after glucose treatments. The enzymes studied are presented inside blue spheres (HK, PK, GS, GSK3, PGM, GDE, PEPCK and GP). Arrows next to the enzymes $(\downarrow \wedge)$ represent the oscillations in enzymatic activity and transcriptional response. Small spheres next enzymes $(O)$ indicate no variations in these enzymes or genes compared with the control. Dashed line involves several enzymes steps in the pathway, and solid lid represents one enzymatic step. The low-glucose (B) and high-glucose (C) are compared with the control (A).

\section{Methods}

\subsection{BME26 Cell Line}

Cells were maintained as previously described [12]. The BME26 cells were maintained in Leibovitz L-15 medium (Gibco BRL, Grand Island, NY, USA) supplemented with amino acids, glucose, mineral salts, and vitamins [45]. During medium preparation, glucose was added at two different concentrations, $50 \mathrm{mM}$ (control-the usual glucose concentration) and $100 \mathrm{mM}$ (high-glucose treatment). The medium was diluted in sterile water (3:1), and then tryptose phosphate broth (10\%), fetal calf serum (10\%), and penicillin/streptomycin $(100 \mathrm{U} / \mathrm{mL}$ and $100 \mu \mathrm{g} / \mathrm{mL}$, respectively) were added. Cells from confluent flasks $\left(25 \mathrm{~cm}^{2}\right)$ were resuspended in fresh complete medium using a 22-gauge needle with bent tip attached to a 5-mL plastic syringe. Culture density was determined using a Neubauer hemocytometer, and cell viability was determined using the trypan blue exclusion technique (0.4\%, Sigma, St. Louis, MO, USA). An aliquot of $1 \times 10^{7}$ viable cells was transferred to $5 \mathrm{~mL}$ (final volume) of fresh complete medium and incubated at $34{ }^{\circ} \mathrm{C}$ for up to two weeks to promote cell proliferation. The medium was replaced weekly to achieve high cell homogeneity. Next, 24-well plates $\left(5 \times 10^{5}\right.$ cells/well) were seeded with cells suspended in $500 \mu \mathrm{L}$ of normal medium, incubated overnight for adhesion. Then, normal medium was completely replaced by either medium without the addition of glucose $50 \mathrm{mM}$ (remaining only with the glucose present in the medium, called low-glucose treatment), with a normal glucose concentration (control), or by a high glucose concentration (high-glucose treatment). In the low-glucose medium, the content of glucose is that present in the medium itself ( $3.125 \mathrm{mM}$ ) (Leibovitz Medium L-15 composition, number L4386-Sigma). All these glucose concentrations were chosen based on the glucose present in the control medium, duplicating this amount or without glucose addition. 


\subsection{Viability Assay}

Cell viability was determined $24 \mathrm{~h}$ after treatment with different media using the MTT assay. Briefly, $50 \mu \mathrm{L}$ MTT ( $5 \mathrm{mg} / \mathrm{mL}$ in PBS) were added on each well. After $2 \mathrm{~h}$ of incubation at $34{ }^{\circ} \mathrm{C}$, the medium was completely discarded, and $1 \mathrm{~mL}$ of acid-isopropyl alcohol $(0.15 \% \mathrm{HCl}$ in isopropyl alcohol) was added to dissolve formazan crystals. The mixture was transferred to $1.5-\mathrm{mL}$ tubes and centrifuged at $6000 \times g$ for $15 \mathrm{~min}$, and the clear supernatant was collected for absorbance measurements at $570 \mathrm{~nm}$ in a UVmini-1240 UV-Vis spectrophotometer Shimadzu (Kyoto, Japan). Unless stated otherwise, the absorbance values of the control treatment were used for normalization (100\% viability).

\subsection{Membrane Integrity Analysis}

BME26 cells were plated $\left(3 \times 10^{5}\right.$ cells/well) onto glass coverslips placed at the bottom of a 24 -well plate. The cells were treated with different glucose concentrations. Subsequently, the cells were directly stained by adding Hoechst $33342(0.4 \mu \mathrm{g} / \mathrm{mL}$, final concentration) for $5 \mathrm{~min}$, followed by staining with propidium iodide ( $2 \mu \mathrm{g} / \mathrm{mL}$, final concentration) for further $2 \mathrm{~min}$. The loss of membrane integrity was detected in cells stained with Hoechst 33342/Propidium iodide observed with pink nuclei under fluorescence microscope (Nikon 80i). Hoechst 33342 permeable cells were stained with blue nuclei. The incubations were performed at room temperature and in the dark. The well contents were discarded, and the coverslips were washed with PBS before being mounted over glass slides with $5 \mu \mathrm{L}$ of glycerol. Cells were observed under a fluorescence microscope (model Eclipse 80i, Nikon, Kanagawa, Japan), and images were obtained at $400 \times$ magnification.

\subsection{Double-Stranded RNA (dsRNA) Synthesis}

Oligonucleotide primers containing $\mathrm{T} 7$ promoter sequence were synthesized for the in vitro transcription and synthesis of dsRNA using RiboMAX ${ }^{\mathrm{TM}}$ Express RNAi System Kit (Promega, Madison, WI, USA). cDNA from 1-day-old tick eggs was used for dsRNA synthesis. The dsRNA was purified according to the manufacturer's instructions, and its concentration was measured at $260 \mathrm{~nm}$. An aliquot of dsRNA was analyzed by agarose gel electrophoresis to check for any degradation. Double-stranded RmGSK3 RNA was synthesized as described previously [12]. The negative control for the RNAi-induced gene silencing was an unrelated dsRNA designed for E. coli $\beta$-galactosidase (kindly donated by Professor Marcos H. Sorgine, Instituto de Bioquímica Médica (IBqM), Universidade Federal do Rio de Janeiro (UFRJ)). The sizes of the synthesized double-stranded RNA complexes were $635 \mathrm{bp}$ for dsAKT, $800 \mathrm{bp}$ for dsCN, and $798 \mathrm{bp}$ for dsGSK.

\section{5. dsRNA Delivery into BME26 Cells}

BME26 cell suspensions were seeded into 24 -well plates $\left(5 \times 10^{5}\right.$ cells/well $)$ to a final volume of $500 \mu \mathrm{L}$ of complete medium. After $24 \mathrm{~h}$ of incubation at $34^{\circ} \mathrm{C}$, the culture medium was replaced with $200 \mu \mathrm{L}$ of fresh medium containing $4.8 \mu \mathrm{g}$ of dsRNA/well, with gentle mixing. Cells were incubated for an additional $24 \mathrm{~h}$ and were harvested for subsequent processing. 


\subsection{RNA Extraction}

Total RNA was extracted from the BME26 cells harvested from 24-well plates using Trizol reagent (Invitrogen, Grand Island, NY, USA) according to the manufacturer's instructions. One microgram of total RNA was reverse transcribed with the High-Capacity cDNA Reverse Transcription-M-MLV kit (Takara Biotechnology, Shiga, Japan). Amplifications were performed on the LightCycler platform (Roche, Göttingen, Germany). Serial dilutions of the cDNA were used to construct a calibration curve. Reaction efficiencies between $85 \%$ and $100 \%$ were determined from calibration curves for each set of primers in $10 \mu \mathrm{L}$ reactions. The $R$. microplus elongation factor-alpha gene (Elf1A) was utilized as reference [46] to normalize the reactions. cDNA from the control BME26 cells was used as a calibrator for the assays. The relative expression of the calibrators was assigned a value of 1 unit. Statistical analyses (means and standard deviation) were performed on data from three independent experiments.

\subsection{Relative Quantification of Metabolism Genes by Real-Time PCR}

A relative transcriptional analysis [47] was conducted with cDNA as a template for quantitative PCR using the LightCycler 480 II platform (Roche, Mannheim, Germany). Serial dilutions of cDNA were used for calibration curve preparation. Reaction efficiencies between $85 \%$ and $100 \%$ were determined from the calibration curves for each set of primers in $10-\mu \mathrm{L}$ reactions. The primers used to amplify the targets are listed in Table 1 . The relative expression was determined using the $\mathrm{Cp}$ values from each run and the Relative Expression Software Tool [47].

Gene sequences for hexokinase (HK), pyruvate kinase (PK), phosphoenolpyruvate carboxykinase (PEPCK), glucose 6-phosphatase (GP), glycogen synthase (GS), phosphoglucomutase (PGM), triose phosphate isomerase (TIM), protein kinase B (AKT), glycogen synthase kinase 3 (GSK3) and glycogen-debranching enzyme (GDE) from different species were retrieved from the GenBank database (Table 1) and used to conduct a BLAST search of an $R$. microplus transcriptome database generated using the Illumina Solexa sequencing platform (BioProject ID PRJNA232001 at Transcriptome Shotgun Assembly (TSA) database, GenBank). The R. microplus gene sequences for TIM, AKT and GSK3 were obtained from GenBank. Specific primers for the genes were designed based on these $R$. microplus sequences (see Table 1). 
Table 1. The sequences of primers used for SYBR Green real-time PCR of genes involved in glycogen metabolism.

\begin{tabular}{|c|c|c|c|c|}
\hline Gene & Primers Used for $R$. microplus Genes & Amplicon Size (bp) & Gene Used as Reference * & $\begin{array}{c}\text { GenBank Access Number of } \\
\text { R. microplus Gene }\end{array}$ \\
\hline Hexokinase & $\begin{array}{l}\text { CATGGACAAAGAGCTTCAACTGCTC } \\
\text { GGAAAGCTCCCTTGACCAGGGTA }\end{array}$ & 150 & $\begin{array}{l}\text { XM_002412706.1 } \\
\text { Ixodes scapularis }\end{array}$ & KF951259 \\
\hline Pyruvate kinase & $\begin{array}{l}\text { GGGCAAGAGGGCAAGACAACTG } \\
\text { CACGTTGAGCACCTTGGTGATG }\end{array}$ & 141 & $\begin{array}{l}\text { XM_002407420.1 } \\
\text { Ixodes scapularis }\end{array}$ & KF951260 \\
\hline Phophoenolpyruvate carboxykinase & $\begin{array}{l}\text { CAAGCAATGAGTGCCTGCCAC } \\
\text { ACAGTCTTCCGTTTTCATCTTG }\end{array}$ & 147 & $\begin{array}{l}\text { XM_002413329.1 } \\
\text { Ixodes scapularis }\end{array}$ & KF951261 \\
\hline Glucose-6-phosphatase & $\begin{array}{l}\text { GGCAGCCATTTGGTACATCATCC } \\
\text { CGACAGGCTGACAATGCACAGG }\end{array}$ & 133 & $\begin{array}{l}\text { XM_002407091.1 } \\
\text { Ixodes scapularis }\end{array}$ & KF951262 \\
\hline Glycogen synthase- 6 & $\begin{array}{l}\text { GCTGGTATCGGGCTGATCCTG } \\
\text { GATGCCTCTGTCTCCAGCCTCC }\end{array}$ & 165 & $\begin{array}{l}\text { XM_002435718.1 } \\
\text { Ixodes scapularis }\end{array}$ & KF951264 \\
\hline Phosphoglucomutase & $\begin{array}{l}\text { CGGATCTGGGCAAGCTGGG } \\
\text { CCGTCGTGACCCTTGATGAGG }\end{array}$ & 151 & $\begin{array}{c}\text { XM_003695907.1 } \\
\text { Apis florea }\end{array}$ & KF951265 \\
\hline Triose phosphate isomerizes & $\begin{array}{l}\text { CCTCGCTGCACAAAATTGCTAC } \\
\text { TCCGAATGACCCAGTATGACCC }\end{array}$ & 128 & & EF014474 \\
\hline Protein kinase $B$ & $\begin{array}{l}\text { GGCCAAAGCCATTCACCTTCA } \\
\text { CСTCCTCACTCGCCAACTTCTC }\end{array}$ & 151 & & JX648548 \\
\hline Glycogen synthase kinase 3 & $\begin{array}{l}\text { CCCACACCCGCTATTTATTG } \\
\text { TGTGCAGGAGAGCCAGTTTA }\end{array}$ & 113 & & EF142066 \\
\hline Glycogen-debranching enzyme & $\begin{array}{l}\text { ATGCTCAGGATCACGCAGAAGC } \\
\text { GTACGTCGGTTGGGAAGGACAAGG }\end{array}$ & 173 & $\begin{array}{l}\text { XM_002401176.1 } \\
\text { Ixodes scapularis }\end{array}$ & \\
\hline
\end{tabular}

* Access numbers of published DNA sequences used to conduct Blast searches for matching gene transcripts in the R. microplus database (PRJNA232001 TSA database). 


\subsection{Hexokinase (HK) Activity}

BME26 cell suspensions were seeded into 24 -well plates $\left(5 \times 10^{5}\right.$ cells/well $)$ to a final volume of $500 \mu \mathrm{L}$ of complete medium and lysate with PBS $(5 \mathrm{mg} / \mathrm{mL})$. The cell lysate was assayed for HK activity in $20 \mathrm{mM}$ Tris- $\mathrm{HCl} \mathrm{pH} 7.5$ containing $6 \mathrm{mM} \mathrm{MgCl}_{2}, 1 \mathrm{mM} \mathrm{ATP}, 0.5 \mathrm{mM} \mathrm{NAD}{ }^{+}$and $10 \mathrm{mM}$ $\mathrm{NaF}$, and the reaction was started with $2 \mathrm{mM}$ glucose. The glucose 6-phosphate that formed was measured by adding an equal volume of $20 \mathrm{mM}$ Tris- $\mathrm{HCl} \mathrm{pH} 7.5,6 \mathrm{mM} \mathrm{MgCl} 2,1 \mathrm{unit} / \mathrm{mL}$ glucose 6-phosphate dehydrogenase from Leuconostoc mesenteroides and $0.3 \mathrm{mM} \beta-\mathrm{NAD}^{+}$. The production of $\beta$-NADH was determined at $340 \mathrm{~nm}$ using a molar extinction coefficient of $6.22 \mathrm{M}^{-1}$, as previously described $[48,49]$.

\subsection{Pyruvate Kinase (PK) Activity}

Samples were prepared as described in the HK activity section. PK activity was measured in $20 \mathrm{mM}$ Tris- $\mathrm{HCl} \mathrm{pH} 7.5,5 \mathrm{mM} \mathrm{MgCl} 2,1 \mathrm{mM}$ ADP, $0.4 \mathrm{mM} \mathrm{NADH}$ and $1 \mathrm{unit} / \mathrm{mL}$ lactate dehydrogenase, and the reaction was started with $1 \mathrm{mM}$ PEP. The $\beta$-NADH consumption was evaluated using a Shimadzu U1240 spectrophotometer at $340 \mathrm{~nm}$, with a molar extinction coefficient of $6.22 \mathrm{M}^{-1}$, as previously described $[48,49]$.

\subsection{Oxygen Consumption}

Total oxygen consumed by BME26 cells after glucose treatments were assayed using a Clark-type electrode (Yellow Springs Instruments Co., Yellow Springs, OH, USA). The calibration process was executed using $100 \%$ as complete air-saturated buffer at $28{ }^{\circ} \mathrm{C}$. Measurements were carried out in $1.5 \mathrm{~mL} 20 \mathrm{mM}$ PBS buffer ( $\mathrm{pH}$ 7.4) and the rate of oxygen consumption was calculated in mmol $\mathrm{O}_{2} / \mathrm{min} / \mathrm{mL}$-cell. A solution containing $1 \mathrm{mM} \mathrm{KCN}$ was added to inhibit cytochrome oxidase. The same solution was used as negative control. Three assays were performed using $1 \times 10^{7}$ cells $/ \mathrm{mL}$ for three independent experiments in triplicate.

\subsection{Statistical Analysis}

The experiments were performed with three independent biological samples in three experimental replicates each, to obtain a mean. All data values were expressed as mean \pm S.D. The ANOVA was used to determine significant differences between groups when data were normally distributed. The $t$-tests were used when comparing data between two groups (Figure 8). The Tukey test was used to compare data between three groups. Significance was set at * $p<0.05 ; * * p<0.001$, ANOVA).

\section{Conclusions}

In conclusion, a number of genes involved in the major pathways for carbohydrate catabolism and anabolism were evaluated in a tick embryonic cell line. The results show that glycogen synthase (GS), glycogen synthase kinase 3 (GSK3), phosphoenolpyruvate carboxykinase (PEPCK) and glucose 6-phosphatase $(G P)$, exhibited mutual regulation in response to glucose treatment. In this sense, both gluconeogenesis enzymes were regulated in a coordinated manner, with similar transcriptional profiles 
with the involvement of $G S K 3$, indicating the correlation between glucose anabolism and catabolism control. Taken together, these results improve the understanding of glucose metabolism in ticks.

\section{Acknowledgments}

The authors are grateful to Marcelle Uhl for technical assistance and the Brazilian agencies FAPERJ, INCT-Entomologia Molecular, CNPq and CAPES for supporting this project.

\section{Author Contributions}

Conceived and designed the experiments: Renato Martins da Silva, Bárbara Della Noce, Camila Fernanda Waltero, Jorge Moraes, Helga Fernandes Gomes, Carlos Logullo. Performed the experiments: Renato Martins da Silva, Bárbara Della Noce, Camila Fernanda Waltero. Analyzed the data: Renato Martins da Silva, Jorge Moraes, Naftaly Wang'ombe Githaka, Evenilton Pessoa Costa, Leonardo Araujo de Abreu. Contributed reagents/materials/analysis tools: Carlos Logullo, Itabajara da Silva Vaz Jr., Satoru Konnai, Kazuhiko Ohashi. Wrote the paper: Renato Martins da Silva, Naftaly Wang'ombe Githaka, Itabajara da Silva Vaz Jr., Carlos Logullo.

\section{Abbreviation}

HK, hexokinase; PK, pyruvate kinase; GS, glycogen synthase; TIM, triose phosphate isomerase; AKT, protein kinase B; GSK3, glycogen synthase kinase 3; PGM, phosphoglucomutase; GDE, glycogen-debranching enzyme; PEPCK, phosphoenolpyruvate carboxykinase; GP, glucose-6 phosphatase; GK, glucokinase.

\section{Conflicts of Interest}

The authors declare no conflict of interest.

\section{References}

1. Parizi, L.F.; Githaka, N.W.; Logullo, C.; Konnai, S.; Masuda, A.; Ohashi, K.; Silva, V.I. The quest for a universal vaccine against ticks: Cross-immunity insights. Vet. J. 2012, 194, 158-165.

2. Grisi, L.; Leite, R.C.; Martins, J.R.S.; Barros, A.T.M.; Andreotti, R.; Cançado, P.H.D.; León, A.A.P.; Pereira, J.B.; Villela, H.S. Reassessment of the potential economic impact of cattle parasites in Brazil. Rev. Bras. Parasitol. Vet. 2014, 23, 150-156.

3. Abreu, L.; Fabres, A.; Esteves, E.; Masuda, A.; Vaz, I.S., Jr.; Daffre, S.; Logullo, C. Exogenous insulin stimulates glycogen accumulation in Rhipicephalus (Boophilus) microplus embryo cell line BME26 via PI3K/AKT pathway. Comp. Biochem. Physiol. B 2009, 153, 185-190.

4. Campos, E.; Moraes, J.; Façanha, A.; Moreira, E.; Valle, D.; Abreu, L.; Manso, P.; Lenzi, H.; Masuda, A.; Vaz, I.S.; Jr.; et al. Kinetics of energy source utilization in Boophilus microplus (Canestrini, 1887) (Acari:Ixodidae) embryonic development. Vet. Parasitol. 2006, 138, 349-357.

5. Moraes, J.; Galina, A.; Alvarenga, P.; Rezende, G.; Masuda, A.; Vaz, I.S., Jr.; Logullo, C. Glucose metabolism during embryogenesis of the hard tick Boophilus microplus. Comp. Biochem. Physiol. A 2007, 146, 528-533. 
6. Saramago, L.; Franceschi, M.; Logullo, C.; Masuda, A.; Vaz, I.S., Jr.; Estrazulas, S.; Moraes, J. Inhibition of enzyme activity of Rhipicephalus (Boophilus) microplus Triosephosphate Isomerase and BME26 cell growth by monoclonal antibodies. Int. J. Mol. Sci. 2012, 13, 13118-13133.

7. Thompson, M.; Stewart, R. Embryonic metabolism and growth in lizards of the genus Eumeces. Comp. Biochem. Physiol. 1997, 118A, 647-654.

8. Vleck, C.; Hoyt, D. Metabolism and energetic of reptilian and avian embryos. In Egg Incubation: Its Effects On Embryonic Development in Birds and Reptiles; Cambridge Univ. Press: Cambridge, UK, 1991; pp. 285-306.

9. Wallace, R. Vitellogenesis and oocyte growth in nonmammalian vertebrates. In Developmental Biology; Browder, L.W., Ed.; Plenum Press: New York, NY, USA, 1985; Volume 1, pp. 127-177.

10. Vital, W.; Rezende, G.; Abreu, L.; Moraes, J.; Lemos, F.; Vaz, I.S., Jr.; Logullo, C. Germ band retraction as a landmark in glucose metabolism during Aedes aegypti embryogenesis. BMC Dev. Biol. 2010, 10, 25.

11. Fabres, A.; de Andrade, C.; Guizzo, M.; Sorgine, M.; Paiva-Silva, G.; Masuda, A.; Vaz, I.S., Jr.; Logullo, C. Effect of GSK-3 activity, enzymatic inhibition and gene silencing by RNAi on tick oviposition and egg hatching. Parasitology 2010, 137, 1537-1546.

12. Esteves, E.; Lara, F.; Lorenzini, D.; Costa, G.; Fukuzawa, A.; Pressinotti, L.; Silva, J.; Ferro, J.; Kurtti, T.; Munderloh, U.; et al. Cellular and molecular characterization of an embryonic cell line (BME26) from the tick Rhipicephalus (Boophilus) microplus. Insect Biochem. Mol. Biol. 2008, $38,568-580$.

13. Lohmeyer, K.; Pound, J.; George, J. Effects of photoperiod on reproduction, nymphal developmental timing, and diapauses in Amblyomma maculatum (Acari: Ixodidae). J. Med. Entomol. 2009, 46, 1299-1302.

14. Randolph, S.; Green, R.; Hoodless, A.; Peacey, M. An empirical quantitative framework for the seasonal population dynamics of the tick Ixodes ricinus. Int. J. Parasitol. 2002, 32, 979-989.

15. Devlin, T. Textbook of Biochemistry with Clinical Correlations, 4th ed.; Wiley-Liss: New York, NY, USA, 1997.

16. Dupriex, V.; Rousseau, G. Glucose response elements in a gene that codes for 6-phosphofructo-2kinase/fructose-2,6-bisphosphatase. DNA Cell. Biol. 1997, 9, 1075-1085.

17. Vaulont, S.; Kahn, A. Transcriptional control of metabolic regulation genes by carbohydrates. FASEB J. 1994, 8, 28-35.

18. Scott, D.; O’Doherty, R.; Stafford, J.; Newgard, C.; Granner, D. The repression of hormone-activated PEPCK gene expression by glucose is insulin-independent but requires glucose metabolism. J. Biol. Chem. 1998, 273, 24145-24151.

19. Towle, H. Metabolic regulation of gene transcription in mammals. J. Biol. Chem. 1995, 270, 23235-23238.

20. Knowles, J.; Albery, W. Perfection in enzyme catalysis: The energetics of triosephosphate isomerase. Acc. Chem. Res. 1977, 10, 105-111.

21. Bell, G.; Burant, C.; Takeda, J.; Gould, G. Structure and function of mammalian facilitative sugar transporters. J. Biol. Chem. 1993, 268, 19161-19164. 
22. Seixas, W.; Gomes-Puyou, A.; Tuena, M.; Moreno-Sanchez, R.; de Felice, F.; de Meis, L. Mitochondrial bound hexokinase activity as a preventive antioxidant defense. J. Biol. Chem. 2004, 279, 39846-39855.

23. Sun, L.; Shukair, S.; Naik, T.; Moazed, F.; Ardehali, H. Glucose phosphorylation and mitochondrial binding are required for the protective effects of hexokinases I and II. Mol. Cell. Biol. 2008, 28, 1007-1017.

24. Pastorino, J.; Hoek, J. Hexokinase II: The integration of energy metabolism and control of apoptosis. Curr. Med. Chem. 2003, 10, 1535-1551.

25. Antonio, F.; Nimmo, G.; Yeaman, S.; Cohen, P. Comparison of the substrate specificities of protein phosphatases involved in the regulation of glycogen metabolism in rabbit skeletal muscle. Biochem. J. 1977, 162, 423-433.

26. Nimmo, G.; Cohen, P. Hormonal control of protein phosphorylation. Adv. Cycl. Nucl. Res. 1977, 8, 124-266.

27. Embi, N.; Rylatt, D.; Cohen, P. Glycogen synthase kinase-3 from rabbit skeletal muscle, separation from cyclic-AMP-dependent protein kinase and phosphorylase kinase. Eur. J. Biochem. 1980, 107, 519-527.

28. Plyte, S.; Hughes, K.; Nikolakaki, E.; Pulverer, B.; Woodgett, J. Glycogen synthase kinase-3: Functions in oncogenesis and development. Biochem. Biophys. Acta 1992, 1114, 147-162.

29. Zhang, W.; Barry, J.; Thompson, J.; Hietakangas, V.; Cohen, S. MAPK/ERK signaling regulates insulin sensitivity to control glucose metabolism in Drosophila. PLoS Genet. 2011, 7, e1002429.

30. Lynedjian, P.; Roth, R.; Fleischmann, M.; Gjinovci, A. Activation of protein kinase B/cAkt in hepatocytes is sufficient for the induction of expression of the gene encoding glucokinase. Biochem. J. 2000, 351, 621-627.

31. Chaodong, W.; Okar, D.; Stoeckman, A.; Peng, L.; Herrera, A.; Herrera, J.; Towle, H.; Lange, A. A potential role for fructose-2,6-bisphosphate in the stimulation of hepatic glucokinase gene expression. Endocrinology 2004, 145, 650-658.

32. Abreu, L.; Calixto, C.; Waltero, C.; della Noce, B.; Wang'ombe, N.; Seixas, A.; Parizi, L.; Konnai, S.; Vaz, I.S., Jr.; Ohashi, K.; et al. The conserved role of the AKT/GSK3 axis in cell survival and glycogen metabolism in Rhipicephalus (Boophilus) microplus embryo tick cell line BME26. Biochim. Biophys. Acta 2013, 1830, 2574-2582.

33. Burgering, B.; Coffer, P. Protein kinase B (c-Akt) in phosphatidylinositol-3-OH kinase signal transduction. Nature 1995, 376, 599-602.

34. Franke, T.; Yang, S.; Chan, T.; Datta, K.; Kazlauskas, A.; Morrison, D.; Kaplan, D.; Tsichlis, P. The protein kinase encoded by the Akt proto-oncogene is a target of the PDGF-activated phosphatidylinositol 3-kinase. Cell 1995, 81, 727-736.

35. Lowry, O.; Passonneau, J. Phosphoglucomutase Kinetics with the Phosphates of Fructose, Glucose, Mannose, Ribose, and Galactose. J. Biol. Chem. 1969, 244, 910-916.

36. White, R.; Nelson, T. Re-evaluation of the subunit structure and molecular weight of rabbit muscle amylo-1,6-glucosidase-4-alpha-glucanotransferase. Biochim. Biophys. Acta 1974, 365, 274-280.

37. Ballard, F.; Oliver, I. Glycogen metabolism in embryonic chick and neonatal rat liver. Biochim. Biophys. Acta 1963, 71, 578-588. 
38. Ballard, F.; Hanson, R.; Leveille, G. Phosphoenolpyruvate carboxykinase and the synthesis of glyceride-glycerol from pyruvate in adipose tissue. J. Biol. Chem. 1967, 242, 2746-2750.

39. Kreisberg, R.; Pennington, L.; Boshell, B. Lactate turnover and gluconeogenesis in normal and obese humans, E effect of starvation. Diabetes 1970, 19, 53-63.

40. Tilghman, S.; Hanson, R.; Reshef, L.; Hopgood, M.; Ballard, F. Rapid loss of translatable messenger RNA of phosphoenolpyruvate carboxykinase during glucose repression in liver. Proc. Natl. Acad. Sci. USA 1974, 71, 1304-1308.

41. Massillon, D. Regulation of the glucose-6-phosphatase gene by glucose occurs by transcriptional and post-transcriptional mechanisms, differential effect of glucose and xylitol. J. Biol. Chem. 2001, 276, 4055-4062.

42. Reshef, L.; Hanson, R.; Ballard, F. A possible physiological role for glyceroneogenesis in rat adipose tissue. Biol. Chem. 1970, 245, 5779-5785.

43. Magnusson, I.; Rothman, D.L.; Katz, L.D.; Shulman, R.G.; Shulman, G.I. Increased rate of gluconeogenesis in type II diabetes mellitus. A 13C nuclear magnetic resonance study. J. Clin. Investig. 1992, 90, 1323-1327.

44. Fernandes, M.; Martins, R.; Costa, E.; Casagrande, E.; Abreu, L.; Vaz, I.S., Jr.; Moreira, L.; Nunes, R.; Logullo, C. The modulation of the symbiont/host interaction between Wolbachia pipientis and Aedes fluviatilis embryos by glycogen metabolism. PLoS One 2014, 9, e98966.

45. Munderloh, U.; Kurtti, T. Formulation of medium for tick cell culture. Exp. Appl. Acarol. 1989, 7, 219-229.

46. Nijhof, A.; Balk, J.; Postigo, M.; Jongejan, F. Selection of reference genes for quantitative RT-PCR studies in Rhipicephalus (Boophilus) microplus and Rhipicephalus appendiculatus ticks and determination of the expression profile of Bm86. BMC Mol. Biol. 2009, 10, 112.

47. Pfaffl, M.W. A new mathematical model for relative quantification in real-time RT-PCR. Nucleic Acids Res. 2001, 29, 1-6.

48. Galina, A.; da Silva, W.S. Hexokinase activity alters sugar-nucleotide formation in maize root homogenates. Phytochemistry 2000, 53, 29-37.

49. Worthington, C. Worthington Enzyme Manual: Enzymes and Related Biochemicals; Worthington Biochemical Corporation: Freehold, NJ, USA, 1988.

(C) 2015 by the authors; licensee MDPI, Basel, Switzerland. This article is an open access article distributed under the terms and conditions of the Creative Commons Attribution license (http://creativecommons.org/licenses/by/4.0/). 